\title{
Electrospun Poly $(y$-glutamate)/Silica Hybrids for Tissue Regeneration: Influences of Silane Coupling Agents on Chemistry, Degradation and Florescent Dye Release
}

\author{
Akiko Obata $^{{ }^{*}}$, Makoto Shimada ${ }^{1}$, Makito Iguchi ${ }^{1}$, Norihiko Iwanaga ${ }^{1}$, Toshihisa Mizuno ${ }^{2}$ and Toshihiro Kasuga ${ }^{1}$ \\ ${ }^{1}$ Division of Advanced Ceramics, Nagoya Institute of Technology, Gokisocho, Showa Ward, Nagoya, Aichi Prefecture 466-8555, Japan \\ ${ }^{2}$ Division of Life and Materials Chemistry, Nagoya Institute of Technology, Gokisocho, Showa Ward, Nagoya, Aichi Prefecture 466-8555, Japan
}

\section{Abstract}

Background: Electrospun hybrids consisting of poly( $\gamma$-glutamate) and silica derived from (3-glycidyloxypropyl) trimethoxysilane (GPTMS) are able to encapsulate proteins with no denaturation because of the water-based synthesis and facilitate the controlled release of encapsulated molecules into buffer solutions. We prepared new types of hybrids using (8-glycidoxyoctyl) trimethoxysilane(GOTMS) in lieu of GPTMS to examine influences of silane coupling agents on chemical structure, degradation behaviour and controlled release of molecules encapsulated in the electrospun hybrids.

Methods: The calcium salt form of the polymer and GOTMS or GPTMS was mixed in water and then electrospun(polymer ratio; $48 \sim 66 \mathrm{wt} \%$ ). Fluorescent dyes with three different molecular weights were added to the hybrid solution $0.5 \mathrm{~h}$ before electrospinning. The electrospun hybrids were characterised with SEM, ATR-FTIR and ${ }^{29} \mathrm{Si}$ MAS/NMR. Degradation and molecule release behaviours of the electrospun hybrids were estimated by soaking them in buffer solutions.

Results: Results of ${ }^{29} \mathrm{Si}$ MAS/NMR demonstrated that polymer/GOTMS hybrids contained highlycondensed siloxane phases than polymer/GPTMS hybrids. Polymer/GOTMS hybrids showed a burst of Si release $12 \mathrm{~h}$ after soaking in buffer solutions and then stopped the release, whereas the polymer/ GPTMS hybrids showed a gradual release in the overall testing time. Some of the GOTMS in the hybrids was expected not to contribute to crosslinking between polymer chains and release from the hybrids immediately. However, the total degradation rate was smaller for the polymer/GOTMS hybrids than for the polymer/GPTMS hybrids. The polymer/GOTMS and polymer/GPTMS hybrids both exhibited molecular release with a molecular-weight dependence; however, the release rate was smaller for polymer/GOTMS than for polymer/GPTMS.

Conclusion: The degradation rate and molecular release behaviour were controlled by changing the cross-linker of the hybrids from GPTMS to GOTMS. This might be because siloxane phases derived from GOTMS became more condensed and GOTMS possesses a lower hydrophilicity than GPTMS.

\section{Introduction}

Electrospun fibres have received increasing attention in the tissue engineering field, because they have a high porosity with interconnected pores, they consist of controlled fibre diameters of nano to micron size, and they exhibit flexibility. The electrospinning process utilises a high voltage source to inject electrical charge to a sample solution, such as polymer/solvent, melt and precursors of solgel glasses. The charged solution flies toward a grounded collector, resulting in the formation of electrospun fibre mats. Aligned fibre sheets and three-dimensional fibrous structurescan also be fabricated with modified electrospinning systems [1-6]. Electrospun fibre mats that are nano to submicron in diameter possess a similar structure to that of the extracellular matrix, therefore various types of electrospun fibre mats have been developed for use in tissue engineering and drug delivery systems (DDS) [7].

Fibre mats of poly ( $\gamma$-glutamate) $(\gamma \mathrm{PGA}) /$ silica hybrids have been developed in our previous work [8-10]. $\gamma$ PGA is a polypeptide that has a secondary amide in the polymer backbone and is degradable by enzyme action. The carboxylic acid group, a high-reactivity functional group, is available as a polymer side chain. Jones et al. developed monoliths of the hybrids containing silica derived from (3-glycidyloxypropyl) trimethoxysilane (GPTMS) and tetraethyl orthosilicate for bone regeneration [11-13]. Hybrids consisting of the

\section{Publication History:}

Received: March 29, 2017

Accepted: May 17, 2017

Published: May 19, 2017

\section{Keywords:}

Electrospinning, Hybrids, Poly $(\gamma-$ glutamate), Silane coupling agents, Tissue Engineering Application calcium salt form of $\gamma$ PGA (Ca- $\gamma$ PGA) cross-linked by silica phases derived from GPTMS are synthesized using water as a solvent[8]. The electrospun $\mathrm{Ca}-\gamma \mathrm{PGA} / \mathrm{GPTMS}$ hybrid fibre mats are flexible and can retain their fibrous structures for several weeks in aqueous solutions. Several types of proteins, such as green fluorescent protein, chymotrypsin and thrombin, were encapsulated in the Ca- $\gamma$ PGA/ GPTMS hybrid fibres and successfully exhibited no denaturation and enzymic activities inside the fibres [9].

The electrospun Ca- $\gamma$ PGA/GPTMS hybrid fibre mats are expected to be good candidates for DDS and tissue engineering scaffolds loading growth factors, as they can encapsulate a wide range of proteins with no deleterious changes of protein structure or function because of their water-based synthesis. Denaturation of proteins can be induced

"Corresponding Author: Dr. Akiko Obata, Nagoya Institute of Technology, Gokisocho, Showa Ward, Nagoya, Aichi Prefecture 466-8555, Japan, Tel: +81(0)427355400; E-mail: obata.akiko@nitech.ac.jp

Citation: Obata A, Shimada M, Iguchi M, Iwanaga N, Mizuno T, et al. (2017) Electrospun Poly(y-glutamate)/Silica Hybrids for Tissue Regeneration: Influences of Silane Coupling Agents on Chemistry, Degradation and Florescent Dye Release. Int J Metall Mater Eng 3: 134. doi: https://doi.org/10.15344/24552372/2017/134

Copyright: (c) 2017 Obata et al. This is an open-access article distributed under the terms of the Creative Commons Attribution License, which permits unrestricted use, distribution, and reproduction in any medium, provided the original author and source are credited. 
Citation: Obata A, Shimada M, Iguchi M, Iwanaga N, Mizuno T, et al. (2017) Electrospun Poly( $\gamma$-glutamate)/Silica Hybrids for Tissue Regeneration: Influences of Silane Coupling Agents on Chemistry, Degradation and Florescent Dye Release. Int J Metall Mater Eng 3: 134. doi: https://doi.org/10.15344/2455-2372/2017/134

Page 2 of 5

by organic solvents [14]. The Ca- $\gamma$ PGA/GPTMS hybrid fibres have a substrate selectivity; no molecules with a high molecular weight $(\mathrm{Mw}>1 \mathrm{kDa})$ can permeate through the fibres and the permeation depends on the molecular sizes for molecules with a low $\mathrm{Mw}$ (Mw $<1 \mathrm{kDa}$ ). This selectivity is expected to be of practical value in some enzyme applications because encapsulated proteins can be protected from proteases or undesirable interactions with biomolecules. Such molecule size-dependence is supposed to depend on the network structure formed by the polymer chains and the cross-linkers in the hybrids. In this study, we prepared a new type of hybrid fibre mats using (8-glycidoxyoctyl) trimethoxysilane (GOTMS) in lieu of GPTMS. GOTMS is a silane coupling agent that has the same functional group as GPTMS (epoxy group) but with a longer carbon spacer. We estimated the influences of silane coupling agents on chemical structures, degradation behaviour and molecular permeation behaviour of the hybrid fibre mats.

\section{Materials and Method}

\section{Preparation of hybrid fibre mats}

Hybrid fibre mats were prepared using the same method as described in the literature [8,9]. We mixed $0.5 \mathrm{~g} \gamma \mathrm{PGA}$ (Mw: 20,00050,000 , Wako Pure Chemical Industries, Japan), $0.129 \mathrm{~g}$ of $\mathrm{Ca}(\mathrm{OH})_{2}$ (Kishida Chemical co., Japan) and $3 \mathrm{ml}$ of ultrapure water and stirred for $0.5 \mathrm{~h}$. The mole ratio of $\gamma \mathrm{PGA}: \mathrm{Ca}(\mathrm{OH})_{2}$ was $20: 9$. We added the (8-glycidoxyoctyl) trimethoxysilane (GOTMS, Shin-Etsu Silicone, Japan) to the resulting solution and stirred for $3 \mathrm{~h}$. The mole ratio of $\gamma$ PGA : GOTMS was $10: 4$ or $10: 2 . \mathrm{Ca}-\gamma$ PGA /GOTMS fibre mats were fabricated with a Nanofibre Electrospinning Unit (Kato Tech Co, Japan). The Ca- $\gamma$ PGA/GOTMS solution was set in a plastic syringe (10 ml, Terumo, Japan). A high tension electric field of $15-20 \mathrm{kV}$ was applied to the needle $(22 \mathrm{G})$ and the tip of the needle was positioned $150 \mathrm{~mm}$ from a collector, grounded rotating drum.Fibre mats were heat-treated at $50^{\circ} \mathrm{C}$ for $6 \mathrm{~h}$. The Ca- $\gamma$ PGA /GPTMS fibre mats were prepared using the same method, except GPTMS was used as a crosslinker. Sample codes of the prepared materials are shown in Table 1. Ratios of $\gamma$ PGA in samples (wt\%) were theoretically calculated on the compositions for the preparation.

\section{Characterisation of the fibre mats}

The morphology of the prepared fibre mats was observed by fieldemission scanning electron microscopy (SEM, JSM-6301F, JEOL, Japan). We used 30 fibres in SEM images for measuring the average fibre diameter and standard deviation. Chemical structures of the prepared fibre mats were characterised by attenuated-total reflection Fourier-transformed infrared spectroscopy (ATR-FTIR, FT-IR4000, JASCO, Japan) and ${ }^{29} \mathrm{Si}$ magic angle spinning nuclear magnetic resonance ( ${ }^{29}$ SiMAS-NMR, JNM-ECA600II, JEOL, Japan). The chemical shifts were measured relative to poly(dimethylsilane). To estimate the degradation behaviour of the fibre mats, $50 \mathrm{mg}$ of samples were soaked in $100 \mathrm{ml}$ of Tris- $\mathrm{HCl}$ buffer solution $(\mathrm{pH}$ $=7.4$ ) and incubated at $36.5^{\circ} \mathrm{C}$ for 9 days. We removed $1 \mathrm{ml}$ of the buffer solution from the sample solution and replenished with a fresh solution at each time point. The removed sample solution was analysed for $\mathrm{Ca}$ and $\mathrm{Si}$ concentrations by inductively coupled plasma atomic emission spectrometry (ICP-AES, ICPS-7000, Shimadzu) (n $=3$ ). To calculate the ratio of released amount of $\mathrm{Ca}$ and Si relative to their total amounts in the samples, the fibre mats were completely dissolved with $\mathrm{NaOH}$ aq. $(20 \mathrm{mM})$ and the $\mathrm{Ca}$ and $\mathrm{Si}$ concentrations of the resulting solution were measured with ICP-AES.

\section{Preparation and characterization of fibre mats encapsulating fluorescent molecules}

Fibre mats encapsulating fluorescent molecules were prepared usinga similar method to that described above, except molecule solutions were added to the hybrid solution before electrospinning. Three different types of fluorescent molecules (Table 2) were added to carbonate-bicarbonate buffer solution $(20 \mathrm{mM}, \mathrm{pH}=9.0)$, resulting in formation of a molecule solution ( $3 \mathrm{mM}$ of molecule concentration). We added $500 \mu \mathrm{l}$ of the prepared molecule solution to the hybrid solution $0.5 \mathrm{~h}$ before electrospinning and then stirred for $0.5 \mathrm{~h}$ (total mixing time: $3 \mathrm{~h}$ ). Electrospinning for the hybrid solution containing the molecule solution was performed using the method described in the previous section. Characterisation with SEM and ATR-FTIR was carried out for the prepared fibre mats encapsulating molecules. For estimation of molecule leakage from the fibre mats, $1.5 \mathrm{mg}$ of the prepared samples was immersed in $3 \mathrm{ml}$ of Tris- $\mathrm{HCl}$ buffer solution (20 mM, pH = 7.5) for $1 \mathrm{~h}$.After removing the fibre mats from the solution, the absorbance $\left(A_{492}\right)$ was monitored to determine the ratio of leakage for each encapsulated molecule $(n=3)$.

\section{Results and Discussion}

Figure 1 shows SEM images of the prepared hybrid fibre mats. All of the prepared fibre mats consisted of submicron-sized fibres. The average diameters of $\mathrm{O}-2 \mathrm{G}, \mathrm{O}-4 \mathrm{G}$ and $\mathrm{P}-2 \mathrm{G}$ were $186 \pm 18,273 \pm 33$ and $222 \pm 51 \mathrm{~nm}$, respectively. The diameter of $\mathrm{O}-2 \mathrm{G}$ was smaller than that of $\mathrm{P}-2 \mathrm{G}$. Since chemical reactivity of functional groups in silane

\begin{tabular}{|l|l|l|l|l|}
\hline & Cross-linker & $\gamma$ PGA $:$ Cross-linker & $\gamma \mathrm{PGA}: \mathrm{Ca}(\mathrm{OH})_{2}$ & Calculated $\gamma$ PGA ratio \\
\hline Sample Code & & $($ mole ratio $)$ & $($ mole ratio $)$ & $($ wt $\%)$ \\
\hline O-2G & GOTMS & $10: 2$ & $20: 9$ & 62 \\
\hline O-4G & GOTMS & $10: 4$ & $20: 9$ & 48 \\
\hline P-2G & GPTMS & $10: 2$ & $20: 9$ & 66 \\
\hline
\end{tabular}

Table 1: Sample codes and chemical compositions.

\begin{tabular}{|l|l|l|l|}
\hline & Molecular weight & Leakage (\%) & \\
\hline Fluorescent molecules & & O-2G & P-2G $^{*}$ \\
\hline Fluorescein & 332 & 39 & 58 \\
\hline FITC-PEG1000 & 1388 & 16 & 20 \\
\hline FITC-PEG2000 & 2388 & 5.6 & 10 \\
\hline
\end{tabular}

Table 2. Fluorescent molecules used and percent leakage of encapsulated molecules after $1 \mathrm{~h}$ of immersion in buffer solution. ${ }^{*}$ Data from reference 9 . 
Citation: Obata A, Shimada M, Iguchi M, Iwanaga N, Mizuno T, et al. (2017) Electrospun Poly( $\gamma$-glutamate)/Silica Hybrids for Tissue Regeneration: Influences of Silane Coupling Agents on Chemistry, Degradation and Florescent Dye Release. Int J Metall Mater Eng 3: 134. doi: https://doi.org/10.15344/2455-2372/2017/134

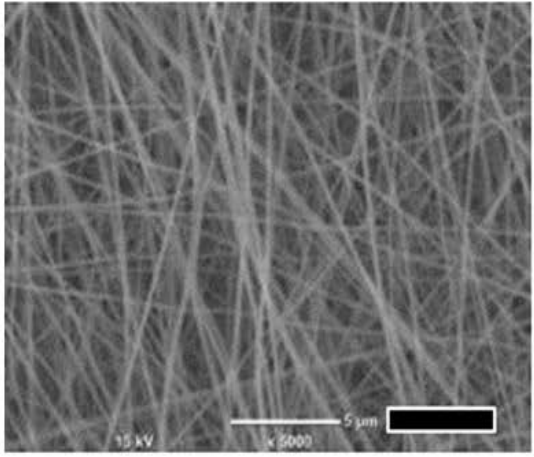

(a)

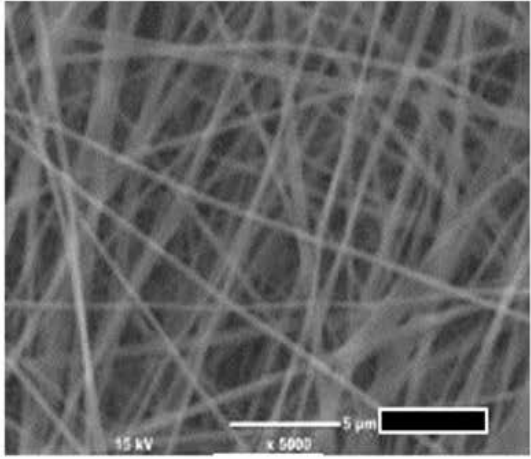

(b)

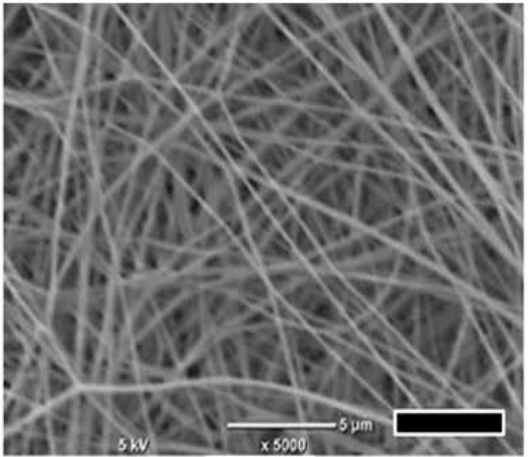

(c)

Figure 1: SEM images of prepared hybrid fibre mats. (a) O-2G, (b) O-4G and (c) P-2G. Bar: $5 \mu \mathrm{m}$. All of the prepared fibre mats consisted of submicron-sized fibres. The average diameters of $\mathrm{O}-2 \mathrm{G}, \mathrm{O}-4 \mathrm{G}$ and $\mathrm{P}-2 \mathrm{G}$ were $186 \pm 18,273 \pm 33$ and $222 \pm 51 \mathrm{~nm}$, respectively.

coupling agents are influenced by the variable length of the spacers, the ratio of crosslinking formed in the hybrid systems and/or viscosity of the solution used for electrospinning would be different between $\mathrm{O}$-series and P-series, causing the observed differences in fibre diameters of the resulting fibre mats $[15,7]$.

Figure 2 shows ATR-FTIR spectra of the fibre mats and raw chemicals used for preparing them. Peaks in all of the spectra of the fibre mats were similar to each other. Bands at $1700-1740 \mathrm{~cm}^{-1}$ were attributed to $\mathrm{C}=\mathrm{O}$ vibration of carboxyl groups [16]. Peaks at around $1740 \mathrm{~cm}^{-1}$ were attributed to crosslinking between epoxy groups in GOTMS or GPTMS and carboxyl groups in Ca- $\gamma$ PGA [17]. Si-O-Si bonds, which were formed due to condensation between silanol groups in GOTMS or GPTMS, which was observed in the fibre mats[18]. Peak shifts at around $1100 \mathrm{~cm}^{-1}$ were found between O-series and $\mathrm{P}$-series; the peaks for $\mathrm{O}-2 \mathrm{G}$ appeared at a higher wave number than P-2G. These peak shifts are likely to be due to changes in siloxane structures formed between $\mathrm{O}-2 \mathrm{G}$ and $\mathrm{P}-2 \mathrm{G}$. This is supported by the ${ }^{29} \mathrm{Si}$ MAS-NMR spectra (Figure 3 ) and the results of the degradation

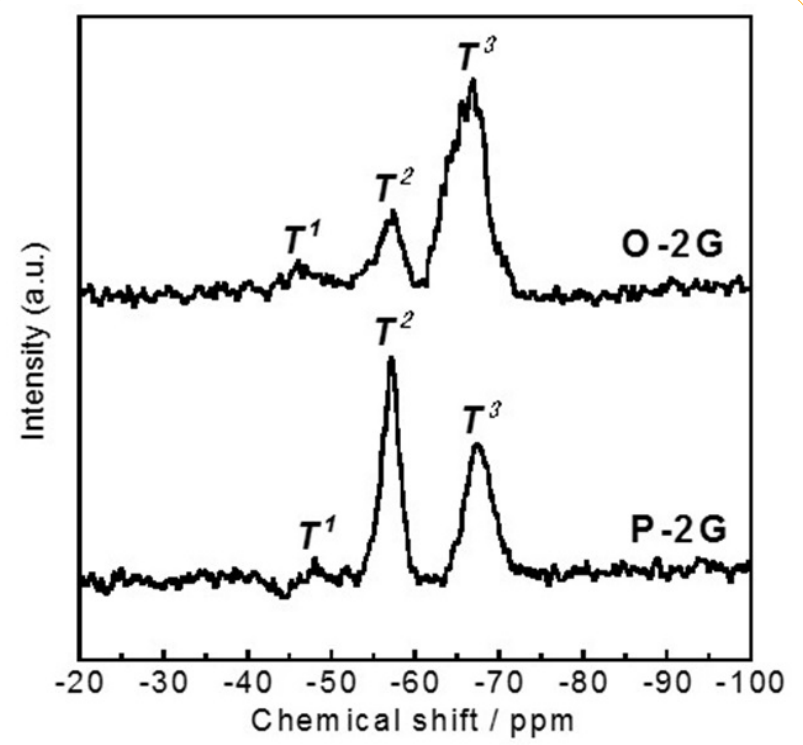

Figure 3: ${ }^{29} \mathrm{Si}$ MAS-NMR spectra of prepared hybrid fibre mats. $\mathrm{T}^{1-3}$ species were formed in the hybrids. The peak area of $\mathrm{T}^{3}$ was the largestin the $\mathrm{O}-2 \mathrm{G}$ spectrum, whereas the $\mathrm{T}^{2}$ and $\mathrm{T}^{3}$ peak areas were similar in the $\mathrm{P}-2 \mathrm{G}$ spectrum.

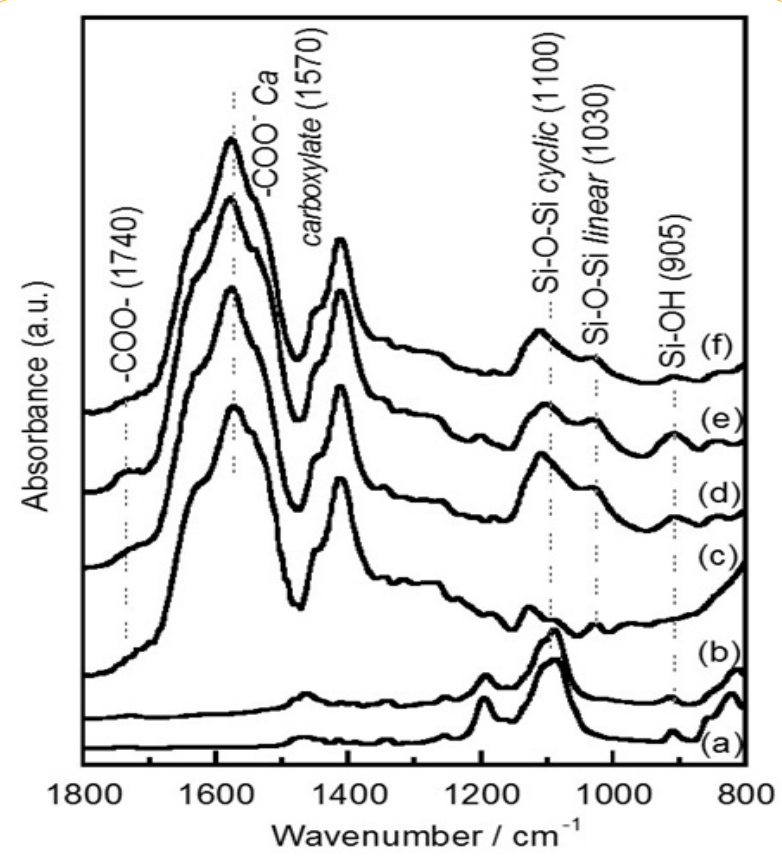

Figure 2: ATR-FTIR spectra of prepared hybrid fibre mats and raw chemicals. (a) GPTMS, (b) GOTMS, (c) Ca- $\gamma$ PGA, (d) O-4G, (e) P-2G and (f) O-2G. Peaks corresponding to the crosslinking between carboxyl groups of $\gamma$ PGA and epoxy groups of GOTMS or GPTMS and siloxane phases were observed at about $1740 \mathrm{~cm}^{-1}$ and $1100 / 1030 \mathrm{~cm}^{-1}$, respectively.

tests (Figure 4). In the ${ }^{29} \mathrm{Si}$ MAS-NMR spectra, the Tn sites indicate a silicon atom bonding to one carbon atom ( $\mathrm{Si}-\mathrm{C}$ ) and to $\mathrm{n}$ bridging oxygen bonds $\left(\mathrm{CSi}(\mathrm{OSi})_{n}(\mathrm{OH})_{3-n}\right)[19]$. Both $\mathrm{O}-2 \mathrm{G}$ and $\mathrm{P}-2 \mathrm{G}$ spectra indicate the presence of $\mathrm{T}^{1}\left(-50 \mathrm{~cm}^{-1}\right), \mathrm{T}^{2}\left(-60 \mathrm{~cm}^{-1}\right)$ and $\mathrm{T}^{3}\left(-70 \mathrm{~cm}^{-1}\right)$ species. Since no $\mathrm{T}^{0}$ peak was observed, most of the silanol groups in the samples were found to bond with each other (condensation). The largest peak area in the $\mathrm{O}-2 \mathrm{G}$ spectrum was that of $\mathrm{T}^{3}$, whereas the peak areas of $T^{2}$ and $T^{3}$ were similar to each other in the P-2G spectrum. This indicates that siloxane phases in $\mathrm{O}-2 \mathrm{G}$ consist of more condensed siloxane than $\mathrm{P}-2 \mathrm{G}$.

Figure 4 shows the percentage $\mathrm{Si}$ and $\mathrm{Ca}$ release of elements contained in the fibre mats. The O-series exhibited a burst of Si and Ca release at $12 \mathrm{~h}$ after soaking. Although the percentage values of Si release 
Citation: Obata A, Shimada M, Iguchi M, Iwanaga N, Mizuno T, et al. (2017) Electrospun Poly( $\gamma$-glutamate)/Silica Hybrids for Tissue Regeneration: Influences of Silane Coupling Agents on Chemistry, Degradation and Florescent Dye Release. Int J Metall Mater Eng 3: 134. doi: https://doi.org/10.15344/2455-2372/2017/134

Page 4 of 5
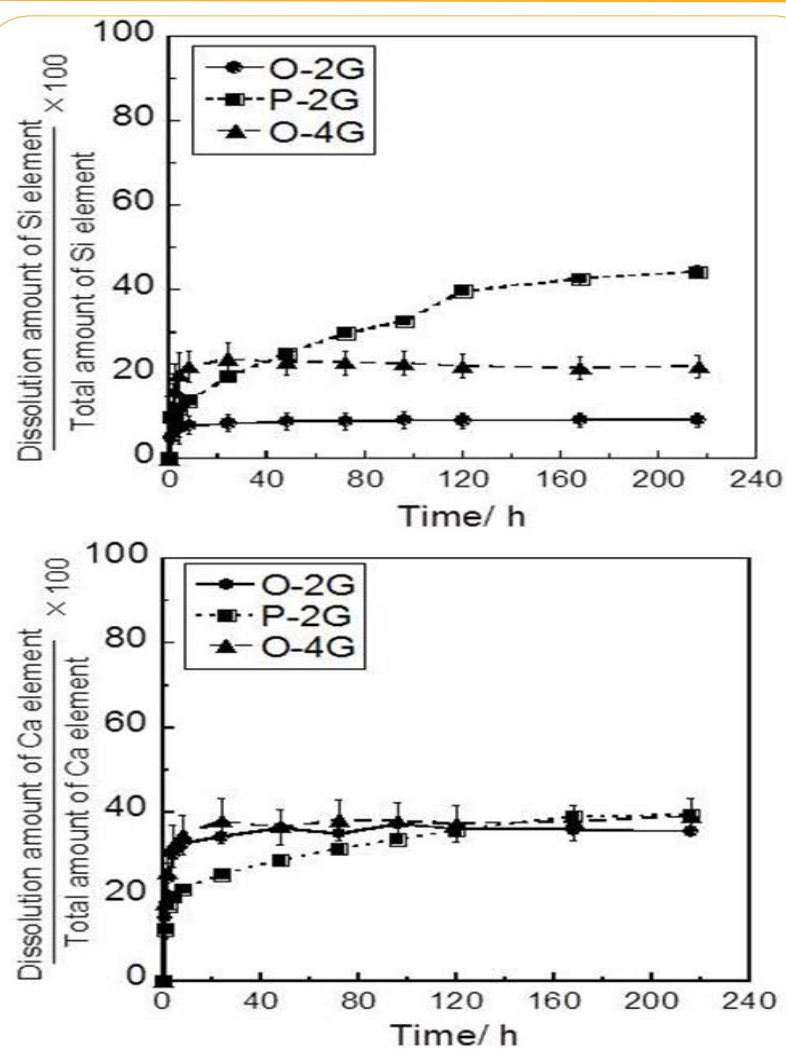

Figure 4: Percentage Si and Ca release of elements contained in fibre mats after soaking in a buffer solution.O-2G and $\mathrm{O}-4 \mathrm{G}$ showsa burst of $\mathrm{Si}$ and $\mathrm{Ca}$ release at $12 \mathrm{~h}$ after soaking, whereas $\mathrm{P}-2 \mathrm{G}$ shows a gradual $\mathrm{Si}$ release and smaller burst of Ca release.

were different between $\mathrm{O}-2 \mathrm{G}$ and $\mathrm{O}-4 \mathrm{G}$, those of Ca release were almost the same. Releases of both elements from $\mathrm{O}$-series stopped after the burst and the percentage $\mathrm{Si}$ and $\mathrm{Ca}$ release values remained equal. In the case of $\mathrm{P}-2 \mathrm{G}$, the Si release behaviour was clearly different to that of the $\mathrm{O}$-series; the percentage release values gradually increased with the immersion time and continued to increase until the end of the immersion test ( $\sim 9$ days). The Ca release exhibited a burst at $12 \mathrm{~h}$ after soaking and then its percentage $\mathrm{Si}$ and Ca release values gradually increased with time. The burst of Si release from the O-series may be attributed to the GOTMS that did not contribute to the crosslinking in the hybrid system. Most of them are expected to have formed siloxane, sinceno $\mathrm{T}^{0}$ peak was observed in the ${ }^{29} \mathrm{Si}$ MAS/NMR for O-2G. The amount of GOTMS that formed free siloxane phases in the hybrids varied with the GOTMS amounts used, since the percentage values of Si release from O-4G were almost twice those from $\mathrm{O}-2 \mathrm{G}$. However, most of the GPTMS contributed to the crosslinking in the hybrid system because the Si release of $\mathrm{P}-2 \mathrm{G}$ was gradual.The total amounts of Si release from P-2G, however, were more than four times those from $\mathrm{O}-2 \mathrm{G}$. This indicates that the crosslinking was more stable with GOTMS than GPTMS. More condensed siloxane phases formed in the $\mathrm{O}$-series might contribute to the lower degradation behaviour Although the Si release behaviour was different between O-2G and $\mathrm{O}-4 \mathrm{G}$, the Ca release was almost the same between the two samples. Therefore, $\mathrm{Ca}^{2+}$ ions must coordinate to carboxyl groups in the polymer chains instead of the siloxane phase.

The results of the molecule leakage test are shown in Table 2. Low $\mathrm{Mw}$ molecules were able to permeate the $\mathrm{O}-2 \mathrm{G}$ fibres like $\mathrm{P}-2 \mathrm{G}$ and their leakage level was dependent on their Mw. However, the percentage leakage decreased when changing the cross-linker from GPTMS to GOTMS.We further confirmed there were almost no differences in fibre diameters and chemical structures of the molecules encapsulated in the samples between SEM observations and ATRFTIR spectra (Figure 5). Encapsulating the molecules was found not to influence the fibre morphology and the chemical structure of the hybrids.
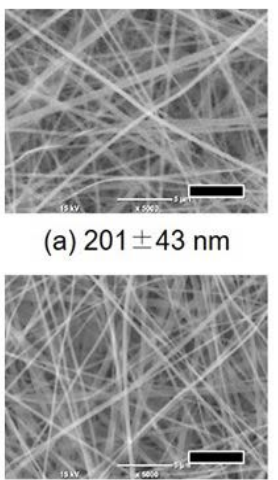

(b) $187 \pm 38 \mathrm{~nm}$

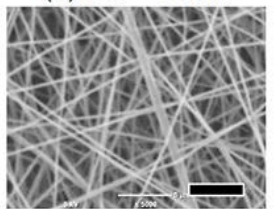

(c) $205 \pm 30 \mathrm{~nm}$ (a) $201 \pm 43 \mathrm{~nm}$

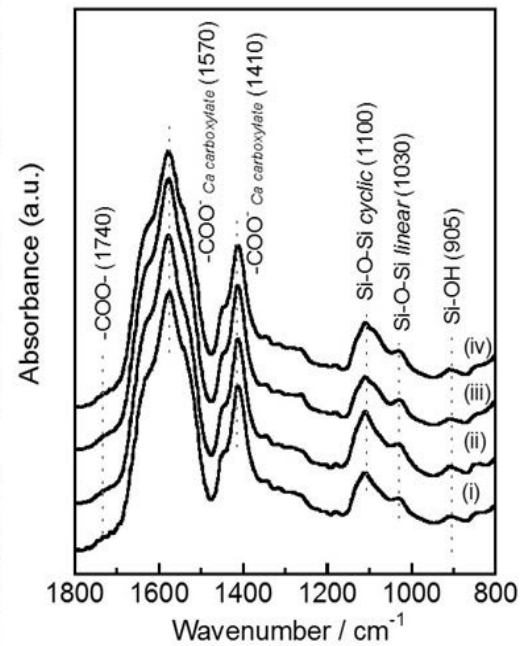

(d)
Figure 5: Results of characterisation of the fibre mats encapsulating fluorescent molecules by (a-c) SEM and (d) ATR-FTIR and average fibre diameters measured with SEM images. (a) fluorescein, (b) FITC-1000 and (c) FITC-2000. (d-i) O-2G, (d-ii) FITC-2000, (d-iii) FITC-1000 and (div) fluorescein. Bar in SEM images: $5 \mu \mathrm{m}$.

Although further investigations will be needed to clarify the effects of cross-linkers on the molecule leakage, we expect that the reduction of the molecule leakage was due to the varied swelling behaviours of the hybrid system in the buffer solution. Cross-linked $\gamma$ PGA is one of the super absorbent polymers [20]. These super-absorbent polymers are polymer-based hydrogels that can absorb water at $>95 \%$ of the total weight or volume. Some hydrogels exhibit controlled release of encapsulated proteins, drugs etc. [21]. Their release depends upon swelling and shrinking of hydrogels. Therefore, both O-series and P-series hybrid fibres are expected to absorb water (swell) after soaking in the buffer solution and then release encapsulated molecules. Since GOTMS contains a longer carbon chain, which reduces hydrophilicity of the hybrid fibres, the swelling of the O-2G fibres was suppressed and the molecule permeation in the fibres was inhibited. In addition, the network mesh size, which is formed by cross-linked polymer chains in hydrogels, is an important parameter for controlling the swelling of hydrogels and the release of encapsulated proteins and drugs [21].

The network mesh size in the hybrid fibres is supposed to change as a result of using different cross-linkers, because the $\mathrm{O}$ - and P-series hybrid fibres vary in both the length of carbon chains in their molecules and in the rate of condensation of siloxane phases formed. This is likely to have induced the varied molecule leakage observed in the present study. The varied swelling behaviour was also expected to have influenced their degradation rate. Thus, the degradation rate and the leakage of molecules encapsulated in the fibres were controlled by the use of GOTMS instead of GPTMS. 
Citation: Obata A, Shimada M, Iguchi M, Iwanaga N, Mizuno T, et al. (2017) Electrospun Poly( $\gamma$-glutamate)/Silica Hybrids for Tissue Regeneration: Influences of Silane Coupling Agents on Chemistry, Degradation and Florescent Dye Release. Int J Metall Mater Eng 3: 134. doi: https://doi.org/10.15344/2455-2372/2017/134

Page 5 of 5

\section{Conclusions}

We compared two different types of the $\gamma \mathrm{PGA} /$ silica hybrid fibre mats prepared using GOTMS or GPTMS as cross-linkers. The degradation behaviour and the release rate of the fluorescent molecules were smaller for the $\gamma \mathrm{PGA} / \mathrm{GOTMS}$ hybrids than the $\gamma \mathrm{PGA} / \mathrm{GPTMS}$ hybrids. The chemical durability and the molecule release behaviours of the hybrids were controllable using proper cross-linkers, which will be useful for developing ideal materials for tissue engineering and DDS.

\section{Competing Interests}

The authors declare that they have no competing interests.

\section{Acknowledgments}

We would like to thank ORTHOREBIRTH Co. Ltd. (Japan) for their helpful discussion in part in developing the materials. We thank Shin-Etsu Silicone (Japan) for kindly providing GOTMS.

\section{Funding}

This work was supported in part by the JSPS Program for Advancing Strategic International Networks to Accelerate the Circulation of Talented Researchers.

\section{References}

1. Jose MV, Thomas V, Johnson KT, Dean DR, Nyairo E (2009) Aligned PLGA HA nanofibrous nanocomposite scaffolds for bone tissue engineering. Acta Biomater 5: 305-315.

2. Aviss KJ, Gough JE, Downes S (2010) Aligned electrospun polymer fibres for skeletal muscle regeneration. Eur Cell Mater 19: 193-204.

3. Schneider OD, Loher S, Brunner TJ, Uebersax L, Simonet M et al. (2008) Cotton wool-like nanocomposite biomaterials prepared by electrospinning: In vitro bioactivity and osteogenic differentiation of human mesenchymal stem cells. J Biomed Mater Res Part B 84B: 350-362.

4. Yokoyama Y, Hattori S, Yoshikawa C, Yasuda Y, Koyama H et al. (2009) Novel wet electrospinning system for fabrication of spongiform nanofiber 3-dimensional fabric. Mater Lett 63: 754-756.

5. Obata A, Ozasa H, Kasuga T, Jones J (2013) Cotton wool-like poly(lactic acid)/vaterite composite scaffolds releasing soluble silica for bone tissue engineering. J Mater Sci-Mater Med 24: 1649-1658.

6. Kasuga T, Obata A, Maeda H, Ota Y, Yao X, et al. (2012) Siloxanepoly(lactic acid)-vaterite composites with 3D cotton-like structure. J Mater Sci-Mater Med 23: 2349-2357.

7. Sill TJ, von Recum HA (2008) Electrospinning: Applications in drug delivery and tissue engineering. Biomaterials 29: 1989-2006.

8. Obata A, Ito S, Iwanaga N, Mizuno T, Jones JR, et al. (2014) Poly([gamma]glutamic acid)-silica hybrids with fibrous structure: effect of cation and silica concentration on molecular structure, degradation rate and tensile properties. RSC Adv 4: 52491-52499.

9. Koeda S, Ichiki K, Iwanaga N, Mizuno K, Shibata M, et al. (2016) Construction and Characterization of Protein-Encapsulated Electrospun Fibermats Prepared from a Silica/Poly(y-glutamate) Hybrid. Langmuir 32 221-229.

10. Gao C, Ito S, Obata A, Mizuno T, Jones JR, et al. (2016) Fabrication and in vitro characterization of electrospun poly ( $\mathrm{Y}$-glutamic acid)-silica hybrid scaffolds for bone regeneration. Polymer 91: 106-117.

11. Valliant EM, Romer F, Wang D, McPhail DS, Smith ME, et al. (2013) Bioactivity in silica/poly( $\mathrm{\gamma}$-glutamic acid) sol-gel hybrids through calcium chelation. Acta Biomater 9: 7662-7671.
12. Poologasundarampillai G, Ionescu C, Tsigkou O, Murugesan M, Hill RG, et al. (2010) Synthesis of bioactive class II poly(y-glutamic acid)/silica hybrids for bone regeneration. J Mater Chem 20: 8952-8961.

13. Poologasundarampillai G, Yu B, Tsigkou O, Valliant E, Yue S, et al. (2012) Bioactive silica-poly( $\gamma$-glutamic acid) hybrids for bone regeneration: Effect of covalent coupling on dissolution and mechanical properties and fabrication of porous scaffolds. Soft Matter 8 : 4822-4832.

14. Ji W, Sun Y, Yang F, van den Beucken JJP, Fan M, et al. (2011) Bioactive Electrospun Scaffolds Delivering Growth Factors and Genes for Tissue Engineering Applications. Pharm Res 28: 1259-1272.

15. Baumgarten PK (1971) Electrostatic spinning of acrylic microfibers. J Colloid Interface Sci 36: 71-79.

16. Ho GH, Ho TI, Hsieh KH, Su YC, Lin PY, et al. (2006) y-polyglutamic acid produced by Bacillus subtilis (natto): Structural characteristics, chemical properties and biological functionalities. J Chin Chem Soc 53: 1363-1384.

17. Zhu J, Kim J, Peng H, Margrave JL, Khabashesku VN, et al. (2003) Improving the dispersion and integration of single-walled carbon nanotubes in epoxy composites through functionalization. Nano Lett 3: 1107-1113.

18. Oliver MS, Blohowiak KY, Dauskardt RH (2010) Molecular structure and fracture properties of ZrOX/Epoxysilane hybrid films. J Sol-Gel Sci Techn 55: 360-368.

19. Yabuta T, Tsuru K, Hayakawa S, Ohtsuki C, Osaka A (2000) Synthesis of Bioactive Organic-Inorganic Hybrids with $\mathrm{y}$-Methacryloxypropyltrimethoxys ilane. J Sol-Gel Sci Techn 19: 745-748

20. Sung MH, Park C, Kim C-J, Poo H, Soda K, et al. (2005) Natural and edible biopolymer poly-y-glutamic acid: synthesis, production, and applications. Chem Rec 5: 352-366.

21. Lin CC, Metters AT (2006) Hydrogels in controlled release formulations: Network design and mathematical modeling. Adv Drug Deliv Rev 58: 13791408.

This article was originally published in a special issue:

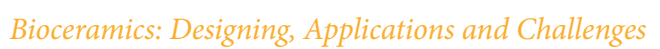

Handled by Editor(s):

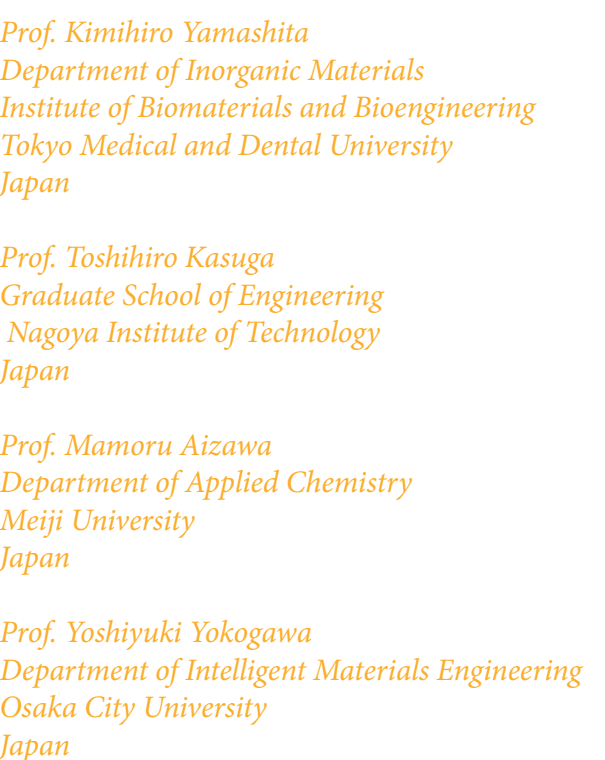

Japan 